\title{
Sanxhaku i Dukagjinit dhe dy regjistrimet e viteve 1571 dhe 1591
}

\section{Lezha, Debri, Spasi, Puka, Iballa, Fanti i Madh dhe i Vogël, Mirdita, Zadrima dhe Rragami}

\section{Ermal Nurja}

Sanxhaku i Dukagjinit ishte një ndër sanxhaqet që formonin vilajetin e Rumelisë gjatë periudhës së sundimit klasik osman. Rumelija ishte një nga dy nënndarjet e mëdha administrative të Perandorisë Osmane, që bashkë me Vilajetin e Anadollit lindën dhe u zhdukën së bashku me Perandorinë (në periudha të caktuara të historisë osmane ka pasur edhe nëndarje të tjera të mëdha siç qe ajo e Hixhazit dhe e Afrikës Veriore që qenë më jetëshkurtra).

Në lidhje me themelimin e sanxhakut të Dukagjinit janë përcaktuar nga historianët dhe studiuesit data të ndryshme, në varësi të dokumentacioneve historike qëata kanë pasur në dispozicion. Gjithashtu nuk mund tëanashkalohet mundësia që sanxhaku të ketë ekzistuar në periudha të ndryshme, mes të cilave edhe nëse de jure ka ekzistuar, de facto pushteti osman nuk ka ekzistuar.

Duke pasur parasysh këtë fakt mund të themi se data e dokumentuar e themelimit të parë të Sanxhakut të Dukagjinit është viti $1436 .{ }^{1}$ Kjo datë e dokumentuar na lejon të krijojmë hipotezën se Sanxhaku i Dukagjinit së bashku me pjesën tjetër të Sanxhakut Arvanid duhet të jetë krijuar gjatë sundimit të sulltan Mehmetit I, pas viteve 1415. Me shumë gjasa treva e Dukagjinit, më saktë një pjesë e saj u përfshi në mosbindjen e përgjithshme që filloi me kryengritjen e Skënderbeut pas vitit 1444. Mjafton të kujtojmë se regjistruesit e regjistrit të Sanxhakut të Dukagjinit kazanë e Spasit, Pukës dhe Iballës i kanë regjistruar edhe me emrat Pulti i Lekës, ndërsa në një rast e kanë regjistruar në formën Pulti i Lekë Zaharisë. Situata duhet të

1 Osmanlı Arşiv Belgelerinde Arnavutluk / Shqipëria në dokumentet arkivale otomane, Botim i Arkivit Osman, İstanbul 2008, fq. 270. 


\section{Albanon}

\section{Revistë kulturore}

ketë vazhduar e tillë deri në vitin 1468 , kur pas fushatës osmane të drejtuar nga Mehmeti II u krye edhe regjistrimi i trevave që kishin marrë pjesë në kryengritjen e Skënderbeut dhe u ndërtua kalaja e Elbasanit. ${ }^{2}$

Sanxhaku i Dukagjinit dokumentohet për herë të dytë në regjistrin e taksës së xhizjes së Rumelisë në vitin 1491, ndonëse kadiu i Dukagjinit njoftonte se nuk ishte e lehtë për t'u grumbulluar mbledhja e xhizjes në këtë sanxhak.

Në lidhje me regjistrimin e detajuar të sanxhakut të Dukagjinit deri më sot janë konstatuar vetëm dy regjistra të llojit tahrir.

Regjistri i parë gjendet në Arkivin Osman të Stambollit, në fondin e Regjistrave Tahrir, me numër 499. Regjistri mban datën 1571 (978 Hixhri).

Regjistri i dytë deri në vitin 2018 gjendej në qytetin e Ankarasë, në Arkivin e Tapive që varet nga Ministria e Punëve Publike. Prej vitit 2018 fondi i regjistrave me vlerë historike u transferua në Arkivin Osman të Stambollit. Ai mban indikacionin arkivor, TKGM, No. 62 dhe ka datën 1591 (evail xhymadelevel $999 \mathrm{H}$ ).

Sanxhaku i Dukagjinit formohej nga kazatë e Debrit, Spasit, Pukës, Iballës, Fandi i Madh, Fandi i Vogël, Mirdita, Rudina, Domoshtica, Pashtrik, Luma, Gora, Opoja, Dibra, Zadrima dhe Rragami.

Në këtë artikull do të trajtohen vetëm një pjesë e kazave, ndërsa në numrin e ardhshëm të revistës Albanon do të trajtohen kazatë e tjera.

Kazatë Grbavçe, Zhupa, Malonshik, Ploshevica, Cetina, Rjeka, Cernica, Grblan i Sipërm dhe Grblan i Poshtëm që janë regjistruar në regjistrin e vitit 1571 të sanxhakut të Dukagjinit, megjithëse nuk bënin pjesë në këtë sanxhak dhe sot gjenden brenda kufijve të Republikës së Malit të $\mathrm{Zi}$, nuk do të trajtohen as në këtë artikull, as në artikullin pasardhës.

Në dallim nga kazatë e tjera të sanxhakut të Dukagjinit, që do të trajtohen në numrin e ardhshëm të revistës Albanon, procesi i islamizimit ende është i ngadaltë edhe në fundin e shekullit të XVI. Myslimanët janë regjistruar në formë vatrash, beqarë dhe të sapomartuar (benak). Tërheq vëmendjen fakti që në disa raste, vatrat myslimane të regjistruara në vitin 1571 nuk shfaqen në vitin 1591. Gjatë kësaj periudhe familjet në fjalë duhet të kenë emigruar në fshatra ose qytete të tjera. Rastet e islamizimeve të regjistruara gjenden në tabelën e mëposhtme:

2 Regjistri osman gjendet në arkivin osman nën referencën arkivore BOA, MAD.d, No. 805. Pjesa për Shqipërinë është përkthyer në shqip dhe gjendet në botimin Selami Pulaha, Lufta shqiptaro-turke në shekullin e XV: Burime osmane, Tiranë 1968, f. 326-374. 


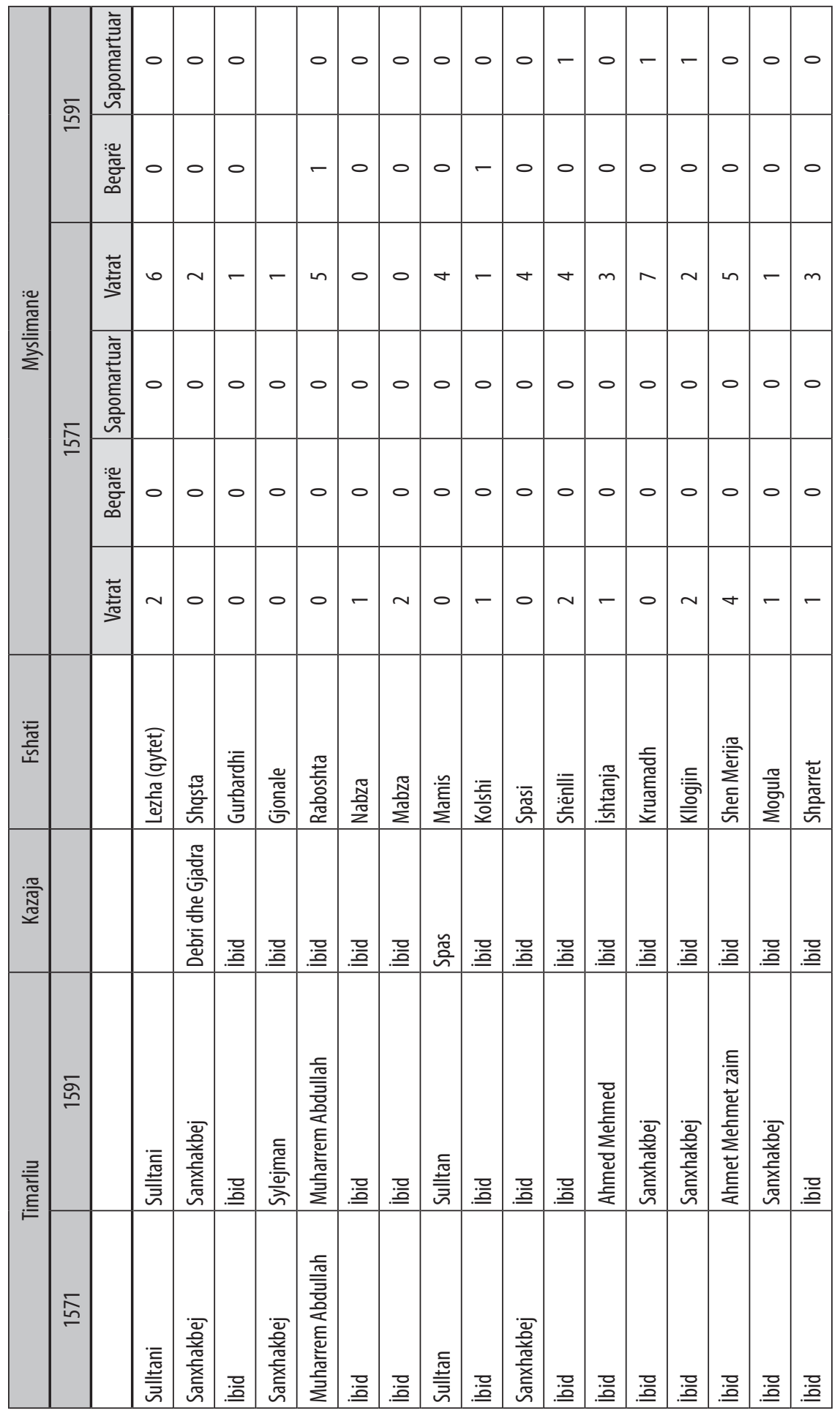




\section{Albanon \\ Revistë kulturore}

\begin{tabular}{|c|c|c|c|c|c|c|c|c|c|c|c|c|c|c|c|c|c|}
\hline \multirow{6}{*}{ 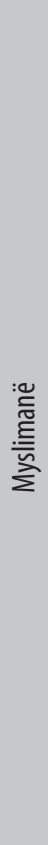 } & \multirow{2}{*}{ 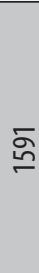 } & 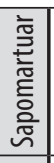 & 0 & $m$ & - & 0 & 0 & 0 & 0 & - & 0 & 0 & 0 & $\sim$ & 0 & 0 & 으 \\
\hline & & 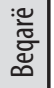 & 0 & - & - & 0 & 0 & 0 & 0 & 0 & 0 & 0 & 0 & 0 & 0 & 0 & $\sigma$ \\
\hline & & 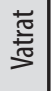 & - & $\sigma$ & $\sim$ & - & - & $m$ & 0 & - & $\sim$ & - & $\sim$ & 0 & 0 & $\sigma$ & $\bar{T}$ \\
\hline & $\Sigma$ & 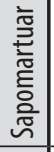 & 0 & 0 & 0 & 0 & 0 & 0 & 0 & 0 & 0 & 0 & 0 & 0 & 0 & 0 & 0 \\
\hline & & 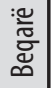 & 0 & 0 & 0 & 0 & 0 & 0 & 0 & 0 & 0 & 0 & 0 & 0 & 0 & 0 & 0 \\
\hline & & 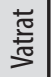 & 0 & $a$ & $m$ & - & - & $m$ & $\sim$ & 0 & 0 & 0 & 0 & 0 & - & 0 & $\hat{m}$ \\
\hline $\begin{array}{l}\text { 䲶 } \\
\text { 닌 }\end{array}$ & & & 宽 & 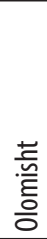 & 올 & 产 & 䒘 & 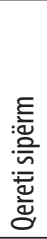 & 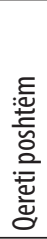 & 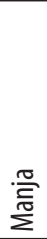 & $\begin{array}{l}\overline{\overline{\bar{o}}} \\
\overline{\bar{c}} \\
\overline{\bar{n}}\end{array}$ & $\begin{array}{l}\overline{\widetilde{0}} \\
\overline{\bar{d}} \\
\bar{n}\end{array}$ & $\tilde{\widetilde{夭}}$ & $\frac{\text { 冚 }}{\frac{\underline{\underline{n}}}{\bar{n}}}$ & 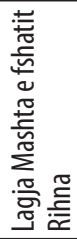 & 莺 & \\
\hline 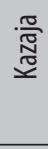 & & & 을 & 을 & 응 & :을 & 䋨 & & & & & & & & 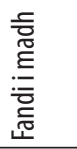 & 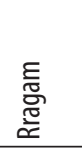 & \\
\hline \multirow[t]{2}{*}{ 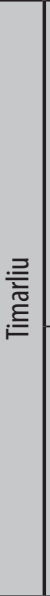 } & ๙ૂ & & 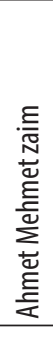 & 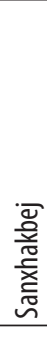 & 을 & 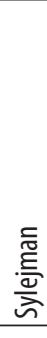 & 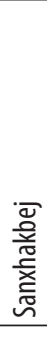 & 을 & 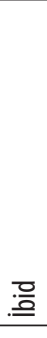 & 을 & 을 & 을 & 을 & $\begin{array}{l}\text { ్ㅠ } \\
\text { 또 }\end{array}$ & 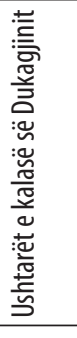 & 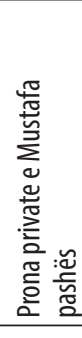 & \\
\hline & $\underset{n}{n}$ & & 을 & 을 & 을 & 을 & 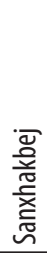 & 豆 & 을 & 豆 & 흥 & 을 & 을 & 을 & $\times$ & 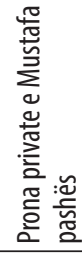 & $\begin{array}{l}\text { 矛 } \\
\text { 잉 }\end{array}$ \\
\hline
\end{tabular}




\section{Qyteti i Lezhës}

Qyteti i Lezhës me kalanë e saj ishte qendra administrative e Sanxhakut të Dukagjinit. Ishulli i Lezhës është regjistruar në statusin truallishtë (mezra) që punohet nga banorët e qytetit të Lezhës. Taksat e tregut të Lezhës, doganës së Lezhës, kripores së Lezhës, kapitenarisë (kapudan) së Lezhës, nxjerrjes së katranit, kripores së Lezhës, martesave dhe akteve penale që kryheshin në qytetin e Lezhës ishin të ardhura që shkonin për llogari të Sulltanit, i cili i administronte me rrugë sipërmarrjeje (mukata). Popullsia e regjistruar si në vitin 1571 ashtu edhe në vitin 1591 formohet vetëm nga vatrat. Nuk ka beqarë, të veja dhe bashtina. Të ardhurat nga taksat e qytetit në vitin 1571 janë 7436 akçe, ndërsa në vitin 1591 janë 8436 akçe. Të ardhurat nga taksat e mukatave në vitin 1571 janë 579'832 akçe, ndërsa në vitin 1591 janë 579'832 akçe. ${ }^{3}$

\section{Kazaja e Debrit dhe Gjadrit}

\begin{tabular}{|c|c|c|c|c|c|c|c|c|}
\hline \multicolumn{2}{|c|}{ Timarliu } & \multirow[t]{2}{*}{ Fshati } & \multicolumn{2}{|c|}{ Vatra } & \multicolumn{2}{|c|}{ Beqar } & \multicolumn{2}{|c|}{ Të ardhura } \\
\hline 1571 & 1591 & & 1571 & 1591 & 1571 & 1591 & 1571 & 1591 \\
\hline Sanxhakbeu & Sanxhakbeu & Mngusha & 22 & 78 & 1 & 2 & 1045 & 1000 \\
\hline ibid & ibid & Korthpula & 20 & 30 & 0 & 4 & 871 & 1871 \\
\hline ibid & ibid & Kaçinar & 9 & 9 & 0 & 0 & 400 & 400 \\
\hline ibid & ibid & Shperdhet & 13 & 12 & 0 & 0 & 564 & 546 \\
\hline ibid & ibid & Gjanis & 18 & 25 & 2 & 2 & 833 & 1000 \\
\hline ibid & ibid & Kalur & 18 & 11 & 2 & 2 & 978 & 1500 \\
\hline ibid & ibid & Shqsta & 8 & 19 & 0 & 2 & 443 & 1000 \\
\hline ibid & ibid & Marshiq & 5 & 21 & 0 & 3 & 251 & 1000 \\
\hline ibid & ibid & Petrabard (Gurbardhi) & 18 & 13 & 3 & 2 & 1029 & 500 \\
\hline ibid & ibid & Kashnjet & 7 & 30 & 1 & 4 & 437 & 1000 \\
\hline ibid & ibid & Rans & 3 & 50 & 0 & 0 & 172 & 1500 \\
\hline ibid & Süleyman & Gjonale & 14 & 6 & 0 & 2 & 764 & 750 \\
\hline ibid & Sanxhakbej & Mirqeshta & 7 & 8 & 0 & 0 & 450 & 450 \\
\hline ibid & ibid & Shkeza & 13 & 18 & 0 & 2 & 620 & 800 \\
\hline ibid & ibid & Bariçor & 12 & 28 & 0 & 7 & 598 & 1400 \\
\hline ibid & ibid & Shtupanz & 6 & 8 & 0 & 0 & 310 & 1000 \\
\hline ibid & ibid & Moriqan truallisht & & & & & 163 & 163 \\
\hline ibid & ibid & Taksa e kullotës & & & & & $x$ & 2000 \\
\hline ibid & ibid & Mosol mezra & & & & & 170 & 170 \\
\hline ibid & ibid & Taksa e rendit e Debrit dhe Gjadrit & & & & & 5000 & 2000 \\
\hline ibid & ibid & Taksa e rendit e Zadrimës & & & & & 4000 & 8000 \\
\hline
\end{tabular}

3 BOA, TT, D. 499, s. 18-20; TKGM, D. 62, vr. 5r-6r,

4 BOA, TT, D. 499, s. 16-33; TKGM, D. 62, vr. 6r-12r. 


\section{Albanon}

\section{Revistë kulturore}

\begin{tabular}{|l|l|l|l|l|l|l|l|l|}
\hline \multicolumn{2}{|c|}{ Timarliu } & \multicolumn{2}{c|}{ Fshati } & \multicolumn{2}{c|}{ Vatra } & \multicolumn{2}{c|}{ Beqar } & \multicolumn{2}{c|}{ Të ardhura } \\
\hline \multicolumn{1}{|c|}{1571} & \multicolumn{1}{|c|}{1591} & & 1571 & 1591 & 1571 & 1591 & 1571 & 1591 \\
\hline $\begin{array}{l}\text { Muharrem } \\
\text { Abdullah }\end{array}$ & $\begin{array}{l}\text { Muharrem } \\
\text { Abdullah }\end{array}$ & Skanda & 41 & 57 & 29 & 7 & 4600 & 4600 \\
\hline ibid & ibid & Balgush & 24 & 28 & 15 & 4 & 2500 & 2500 \\
\hline ibid & ibid & Raboshta & 76 & 18 & 0 & 6 & $X^{5}$ & 3400 \\
\hline ibid & ibid & Nabza & 5 & 14 & 0 & 3 & 330 & 330 \\
\hline ibid & ibid & Mabza & 4 & 20 & 0 & 3 & 340 & 340 \\
\hline ibid & ibid & Vran & 7 & 16 & 0 & 2 & 358 & 358 \\
\hline ibid & ibid & Vela & 7 & 20 & 0 & 6 & 372 & 372 \\
\hline $\begin{array}{l}\text { Spahinjtëe } \\
\text { Dukagjinit }\end{array}$ & X & Merqinja & 128 & $X$ & 30 & $X$ & $X^{8}$ & $X$ \\
\hline Total & & & 485 & 539 & 83 & 63 & $27^{\prime} 598$ & $39^{\prime} 950$ \\
\hline
\end{tabular}

\section{Kazaja e Spasit 9}

\begin{tabular}{|l|l|l|c|c|c|c|c|c|c|c|}
\hline \multicolumn{2}{|c|}{ Timarliu } & \multicolumn{2}{c|}{ Fshati } & \multicolumn{2}{c|}{ Vatra } & \multicolumn{2}{c|}{ Beqar } & \multicolumn{2}{c|}{ Bashtina } & \multicolumn{2}{c|}{ Të ardhura } \\
\hline 1571 & \multicolumn{1}{|c|}{1591} & & 1571 & 1591 & 1571 & 1591 & 1571 & 1591 & 1571 & 1591 \\
\hline Sulltani & Sulltani & Mamis & 26 & 45 & 2 & 7 & 1 & 0 & 3000 & 3000 \\
\hline ibid & ibid & Kolshi & 27 & 38 & 4 & 4 & 1 & 1 & 2000 & 2000 \\
\hline Sanxhakbe & Sanxhakbe & Spas & 10 & 15 & 0 & 0 & 0 & 0 & 466 & 1500 \\
\hline ibid & ibid & Shënlli & 21 & 10 & 3 & 2 & 3 & 6 & 1029 & 1000 \\
\hline ibid & Ahmed Mehmed & Shtupanja & 15 & 18 & 0 & 5 & 2 & 2 & 768 & 800 \\
\hline ibid & Sanxhakbe & Kruamadh & 11 & 11 & 0 & 1 & 0 & 0 & 595 & 1500 \\
\hline ibid & Sanxhakbe & Kllogjin & 7 & 7 & 0 & 0 & 110 & 11 & 436 & 1600 \\
\hline ibid & Ahmet Mehmet zaim & Kalimariş & 21 & 23 & 0 & 5 & 0 & 0 & 973 & 1000 \\
\hline ibid & ibid & Shen Merija & 11 & 15 & 1 & 2 & 1 & 1 & 709 & 1000 \\
\hline ibid & Sanxhakbe & Shen Kroq & 12 & 19 & 0 & 2 & 2 & 2 & 670 & 950 \\
\hline ibid & ibid & Mogula & 16 & 22 & 0 & 3 & 0 & 0 & 761 & 1050 \\
\hline ibid & ibid & Kolomri & 9 & 12 & 0 & 1 & 0 & 0 & 475 & 700 \\
\hline ibid & ibid & Sakat & 12 & 11 & 0 & 1 & 0 & 0 & 782 & 950 \\
\hline ibid & ibid & Darda & 10 & 10 & 0 & 0 & 0 & 0 & 495 & 800 \\
\hline ibid & ibid & Shparret & 14 & 15 & 3 & 3 & 1 & 1 & 1003 & 1000 \\
\hline ibid & Ahmet Mehmet zaim & Peta & 15 & 24 & 4 & 2 & 0 & 1 & 1200 & 1200 \\
\hline
\end{tabular}

5 Regjistruesi e ka lënë bosh

6 Më përpara ka qenë pjesë e sanxhakut të Ohrit më pas u kalua nën varësinë e sanxhakut të Dukagjinit.

7 E regjistruar nga regjistruesi i sanxhakut të Ohrit.

8 Regjistruesi e ka lënë bosh.

9 BOA, TT, D. 499, s. 37-48; TKGM, D. 62, vr. 13v-18v.

10 Bashtina e Kishës së Shën Marisë

11 Bashtina e Kishës së Shën Marisë 


\begin{tabular}{|c|c|c|c|c|c|c|c|c|c|c|}
\hline \multicolumn{2}{|r|}{ Timarliu } & \multirow[t]{2}{*}{ Fshati } & \multicolumn{2}{|c|}{ Vatra } & \multicolumn{2}{|c|}{ Beqar } & \multicolumn{2}{|c|}{ Bashtina } & \multicolumn{2}{|c|}{ Të ardhura } \\
\hline 1571 & 1591 & & 1571 & 1591 & 1571 & 1591 & 1571 & 1591 & 1571 & 1591 \\
\hline ibid & Sanxhakbe & Barniç & 12 & 13 & 3 & 2 & 0 & 1 & 818 & 1250 \\
\hline ibid & ibid & Olomisht & 12 & 22 & 4 & 5 & 0 & 0 & 1500 & 2500 \\
\hline ibid & ibid & Suroj & 21 & 20 & 2 & 2 & 1 & 1 & 2000 & 6000 \\
\hline ibid & Sylejman dhe tjerë & Arren & 14 & 37 & 3 & 7 & 0 & 0 & 1200 & 4000 \\
\hline & & $\begin{array}{l}\text { Taksa e skelës së Spasit } \\
\text { që gjendet në fshatin } \\
\text { Sakat. }\end{array}$ & & & & & & & 8000 & 8000 \\
\hline & & $\begin{array}{l}\text { Taksa e rendit Spas dhe } \\
\text { Puka }\end{array}$ & & & & & & & 3000 & 4000 \\
\hline & & $\begin{array}{l}\text { Klomodiz nuk iu gjet as } \\
\text { nami as nishani }\end{array}$ & & & & & & & & \\
\hline Total & & & 296 & 387 & 29 & 54 & 13 & 13 & 31880 & 45800 \\
\hline
\end{tabular}

Në mesin e kazasë së Spasit në fshatin Sakat kemi dy bazdar (kujdestar fajkonjsh), 1 qefali në fshatin Barniç dhe myselim (të përjashtuar nga taksat) 4 në Barniç, 1 në Kllogjin dhe 2 në Kolshi, që mirëmbajnë urën mbi lumin Leshtenja, si dhe 1 në Shtanja.

Në Olomisht në vitin 1591 kemi dy vatra të ardhura nga fshati Skura.

\section{Kazaja e Pukës, ndryshe quhet edhe Mali $\mathbf{Z i}^{12}$}

Në vitin 1591 në fshatin Bardhed kemi tri vatra të ardhura nga fshati Çagn, në fshatin Ripa kemi një beqar të ardhur nga fshati Dobrishta, në fshatin Dosh kemi një vatër të ardhur nga fshati Kanoz, në fshatin Bilishta/ Belishja kemi 1 vatër të ardhur nga fshati Brataniça.

Kemi 1 qefali në fshatin Ripa, 1 myselim nga fshati Qereti Sipërm, 1 qefali në fshatin Bogdan-Buzan,

Në fshatin Arsti është regjistruar 1 bashtinë, ndërsa në fshatin Qeret i Sipërm është regjistruar 1 çiflig.

\begin{tabular}{|l|l|l|c|c|c|c|c|c|}
\hline \multicolumn{2}{|c|}{ Timarliu } & \multicolumn{2}{c|}{ Fshati } & \multicolumn{2}{c|}{ Vatra } & \multicolumn{2}{c|}{ Beqar } & \multicolumn{2}{c|}{ Të ardhura } \\
\hline \multicolumn{1}{|c|}{1571} & 1591 & & 1571 & 1591 & 1571 & 1591 & 1571 & 1591 \\
\hline Sanxhakbej & Sanxhakbej & Bardhed & 25 & 26 & 0 & 2 & 1059 & 1500 \\
\hline ibid & ibid & Vila & 12 & 36 & 0 & 2 & 505 & 1500 \\
\hline ibid & ibid & Arsti & 13 & 15 & 0 & 2 & 655 & 1000 \\
\hline ibid & ibid & Ripa & 21 & 22 & 0 & 3 & 846 & 1150 \\
\hline ibid & ibid & Kçira & 8 & 5 & 0 & 0 & 354 & 1000 \\
\hline
\end{tabular}

12 BOA, TT, D. 499, s. 53-62, TKGM, D. 62, vr. 19v-24v. 


\section{Albanon}

\section{Revistë kulturore}

\begin{tabular}{|c|c|c|c|c|c|c|c|c|}
\hline \multicolumn{2}{|c|}{ Timarliu } & \multirow[t]{2}{*}{ Fshati } & \multicolumn{2}{|c|}{ Vatra } & \multicolumn{2}{|c|}{ Beqar } & \multicolumn{2}{|c|}{ Të ardhura } \\
\hline 1571 & 1591 & & 1571 & 1591 & 1571 & 1591 & 1571 & 1591 \\
\hline ibid & ibid & Dosh & 13 & 33 & 0 & 7 & 552 & 2500 \\
\hline ibid & ibid & Shkoza & 10 & 5 & 0 & 0 & 521 & 521 \\
\hline ibid & ibid & Qereti sipërm & 12 & 13 & 0 & 0 & 492 & 1500 \\
\hline ibid & ibid & Qereti poshtëm & 11 & 51 & 0 & 15 & 393 & 2000 \\
\hline ibid & ibid & Zenat & 6 & 20 & 0 & 5 & 293 & 500 \\
\hline ibid & ibid & Manja & 15 & 16 & 5 & 4 & 987 & 978 \\
\hline ibid & ibid & Shenkoll & 10 & 9 & 2 & 2 & 575 & 575 \\
\hline ibid & ibid & Dushnjeza & 17 & 11 & 2 & 2 & 815 & 815 \\
\hline ibid & ibid & Lepurushk & 8 & 2 & 3 & 0 & 794 & 274 \\
\hline ibid & ibid & Bogdan-Buzan & 7 & 11 & 2 & 2 & 483 & 484 \\
\hline ibid & ibid & Mirat & 4 & 17 & 0 & 0 & 186 & 1000 \\
\hline ibid & ibid & Shen Pal & 12 & 10 & 4 & 4 & 1134 & 1134 \\
\hline ibid & ibid & Ras & 6 & 28 & 0 & 5 & 210 & 500 \\
\hline ibid & Hasan & Bilishta & 18 & 24 & 2 & 2 & 886 & 1000 \\
\hline ibid & Sanxhakbej & Karma mezra & & & & & 200 & 200 \\
\hline \begin{tabular}{|l} 
Sylejman Ishak ushtari \\
kalasë Dukagjinit
\end{tabular} & $\begin{array}{l}\text { Sylejman Ishak } \\
\text { ushtari kalasë } \\
\text { Dukagjinit }\end{array}$ & Koman mezra & & & & & 600 & 700 \\
\hline ibid & ibid & Dubrova & & & & & 800 & 800 \\
\hline$X$ & Sanxhakbej & $\begin{array}{l}\text { Taksa e rendit e } \\
\text { Pukës }\end{array}$ & & & & & $X$ & 6000 \\
\hline Total & & & 228 & 354 & 20 & 57 & $13^{\prime} 340$ & $27^{\prime} 631$ \\
\hline
\end{tabular}

\section{Kazaja e Iballës ${ }^{13}$}

Në vitin 1591 të ardhurat e kazasë së Iballës shkonin të gjitha për ushtarët e kalasë së Dukagjinit.

Në kazanë e Iballës është regjistruar vetëm 1 bashtinë në fshatin Ilishqa.

\begin{tabular}{|l|l|c|c|c|c|c|c|}
\hline Timarliu & Fshati & \multicolumn{2}{|c|}{ Vatra } & \multicolumn{2}{c|}{ Beqar } & \multicolumn{2}{c|}{ Të ardhura } \\
\hline \multirow{7}{*}{} & & 1571 & 1591 & 1571 & 1591 & 1571 & 1591 \\
\cline { 2 - 8 } & Iballa & 61 & 82 & 18 & 20 & 7500 & 9000 \\
\cline { 2 - 8 } & Ashta & 19 & 36 & 1 & 6 & 1900 & 3400 \\
\cline { 2 - 8 } & Gralisht & 19 & 24 & 2 & 3 & 1995 & 3495 \\
\cline { 2 - 8 } & Fierza & 9 & 12 & 4 & 2 & 1235 & 1435 \\
\cline { 2 - 8 } & Porava & 7 & 7 & 3 & 3 & 950 & 950 \\
\cline { 2 - 8 } & Ripa e Sipërme & 5 & 6 & 1 & 1 & 570 & 570 \\
\hline
\end{tabular}

13 BOA, TT, D. 499, s. 67-76, TKGM, D. 62, vr. 25v-29r. 


\begin{tabular}{|l|l|c|c|c|c|c|c|}
\hline Timarliu & Fshati & \multicolumn{2}{|c|}{ Vatra } & \multicolumn{2}{c|}{ Beqar } & \multicolumn{2}{c|}{ Të ardhura } \\
\hline \multirow{5}{*}{} & & 1571 & 1591 & 1571 & 1591 & 1571 & 1591 \\
\cline { 2 - 8 } & Arsta & 8 & 8 & 1 & 2 & 855 & 855 \\
\cline { 2 - 8 } & Miraskela & 11 & 12 & 4 & 3 & 1425 & 1425 \\
\cline { 2 - 8 } & Frashni & 6 & 10 & 4 & 3 & 950 & 955 \\
\cline { 2 - 8 } & Ripa e poshtme & 12 & 16 & 3 & 3 & 1425 & 1425 \\
\cline { 2 - 8 } & Ilishqa & 8 & 16 & 1 & 3 & 950 & 1950 \\
\cline { 2 - 8 } & Dobruna & 12 & 16 & 4 & 4 & 1520 & 1520 \\
\cline { 2 - 8 } & Sopan & 18 & 30 & 6 & 6 & 2280 & 3380 \\
\cline { 2 - 8 } & Blçna & 19 & 28 & 8 & 4 & 2565 & 2565 \\
\cline { 2 - 8 } & Shupan & 24 & 23 & 5 & 4 & 2755 & 2755 \\
\cline { 2 - 8 } & Mërtur & 19 & 16 & 8 & 3 & 2065 & 2565 \\
\cline { 2 - 8 } & Bab, bosh & 0 & 0 & 0 & & 355 & 355 \\
\hline Total & & 257 & 342 & 73 & 70 & $31^{\prime 2} 295$ & $38^{\prime} 600$ \\
\hline
\end{tabular}

\section{Kazaja e Fandit të Madh ${ }^{14}$}

Në vitin 1591 të ardhurat e kazasë së Fandit të Madh shkonin të gjitha për ushtarët e kalasë së Dukagjinit.

Në vitin 1591 në fshatin Rihna ishte vendosur 1 vatër nga fshati Shakoll dhe 1 nga lagja Mashta e fshatit Rihna. Po ashtu në fshatin Tirdhot është vendosur 1 vatër nga fshati Shakoll.

\begin{tabular}{|c|c|c|c|c|c|c|c|c|}
\hline \multicolumn{2}{|c|}{ Timarliu } & Fshati & \multicolumn{2}{|c|}{ Vatra } & \multicolumn{2}{|c|}{ Beqar } & \multicolumn{2}{|c|}{ Të ardhura } \\
\hline 1571 & 1591 & & 1571 & 1591 & 1571 & 1591 & 1571 & 1591 \\
\hline & & Rihna & 18 & 18 & 0 & 3 & $X$ & $X$ \\
\hline & & Mashta lagje & 13 & 8 & 0 & 5 & 2208 & 2208 \\
\hline & & Todhri & 24 & 25 & 3 & 3 & 1863 & 2863 \\
\hline & & Lukani & 11 & 5 & 1 & 0 & 828 & 828 \\
\hline & & Munella & 16 & 14 & 0 & 0 & $X$ & $X$ \\
\hline & & Kimza mah & 14 & 9 & 1 & 1 & 2139 & 2139 \\
\hline & & Tirdhot & 16 & 12 & 0 & 0 & 1100 & 1100 \\
\hline & & Shkoza & 17 & 11 & 2 & 2 & 1310 & 1300 \\
\hline & & Ishmak & 8 & 6 & 0 & 0 & 552 & 525 \\
\hline & & Qarr mezra, bosh & & & & & & \\
\hline Total & & & 137 & 108 & 7 & 14 & $10^{\prime} 000$ & $10^{\prime} 963$ \\
\hline
\end{tabular}

14 BOA, TT, D. 499, s. 77-82; TKGM, D. 62, vr. 30v-31r 


\section{Albanon}

\section{Revistë kulturore}

\section{Kazaja e Fandit të Vogël ${ }^{15}$}

Në vitin 1571 fshatrat e kazasë së Fandit të Vogël nuk janë regjistruar, veprim që në administratën osmane konsiderohej si formë mosbindjeje. Megjithatë të ardhurat e mundshme që mund të mblidheshin nga ato fshatra janë përcaktuar nga njohës të mirë të kazasë, popullsisë dhe produkteve që mund të mblidhen prej tyre. Kjo gjendje ka ndryshuar në vitin 1591, kur janë regjistruar me emra banorët e atyre fshatrave dhe taksat që ata duhen të pagonin.

\begin{tabular}{|l|l|l|c|c|c|}
\hline Timarliu & Fshati & Vatra & \multicolumn{2}{l|}{ Të ardhura } \\
\hline 1571 & 1591 & & 1591 & 1571 & 1591 \\
\hline Mustafa & Korkud sanxhakbej i Dukagjinit & Pine & 44 & 2879 & 6000 \\
\hline İbid & İbid & Bera & 11 & 2228 & 1228 \\
\hline İbid & Katra & 38 & 1845 & 1845 \\
\hline İbid & Ibid & Gjonm & 48 & 2390 & 1390 \\
\hline İbid & Grid & Ibid & 43 & 656 & 656 \\
\hline Hasan dhe Mustafa & İbid & Shën Gjergj & 6 & 1500 & 1500 \\
\hline İskender Hysen & İbid & Kuqin & 18 & 500 & 500 \\
\hline Mustafa Iljas & İbid & Mirgjesht, hali & & 1400 & 1400 \\
\hline Mustafa & İbid & Ostrojka & & $X$ & 500 \\
\hline Mustafa & İbid & & 0 & 2000 \\
\hline Taksa e rendit Fanta & & & & 0 & 13500 \\
\hline $\begin{array}{l}\text { Taksa e bagëtive e kazave të Debrit, Mirditës, Pukës, } \\
\text { Spasit, Fandit të Madh dhe të Vogël ve İbalës }\end{array}$ & & & & \\
\hline Total & & & 212 & $13^{\prime} 398$ & $31^{\prime} 019$ \\
\hline
\end{tabular}

\section{Kazaja e Mirditës ${ }^{16}$}

Sipas një anëshkrimi që gjendet në regjistrin e vitit 1571 shkruhet se kazaja në fjalë në një regjistër të mëparshëm (defter-i atik), data e të cilit nuk shkruhet, ka qenë e regjistruar nën varësinë administrative të Fandit të Vogël, ndërsa në këtë kohë është krijuar kazaja e Mirditës. Në vitin 1571, me përjashtim të fshatit Blakza e Sipërme dhe e Poshtme, banorët e të cilëve janë regjistruar, 9 fshatrat e tjera që formonin kazanë e Mirditës nuk ishin paraqitur që të regjistroheshin. Vlera e taksës së fshatrave në fjalë në këtë vit është caktuar nga njohësit e zonës (ehl-i vukuf). Në vitin 1591 situata ndryshon. Në këtë vit janë regjistruar me emra edhe banorët e fshatrave të tjera të kazasë së

15 BOA, TT, D. 499, s. 85-86; TKGM, D. 62, vr. 32v-34v.

16 BOA, TT, D. 499, s. 87-89; ; TKGM, D. 62, vr. 35v- 
Mirditës. Beqarë janë regjistruar vetëm në vitin 1571, në total 3 në fshatin Blakza e poshtme, të cilët nuk figurojnë në vitin 1591.

\begin{tabular}{|l|l|l|l|l|l|l|}
\hline \multicolumn{2}{|c|}{ Timarliu } & \multicolumn{1}{c|}{ Fshati } & \multicolumn{2}{c|}{ Vatra } & \multicolumn{2}{c|}{ Të ardhurat } \\
\hline \multicolumn{1}{|c|}{1571} & \multicolumn{1}{|c|}{1591} & & \multicolumn{1}{c|}{1571} & \multicolumn{1}{c|}{1591} & & \\
\hline Hysen İskender & Sanxhakbej & Blakza e poshtme & 14 & 11 & 1200 & 1000 \\
\hline $\begin{array}{l}\text { Ushtarët e kalasë së } \\
\text { Lezhës }\end{array}$ & $\begin{array}{l}\text { Ushtarët e kalasë së } \\
\text { Lezhës }\end{array}$ & Blakza e sipërme & 11 & 8 & 1800 & 1800 \\
\hline & İbid & Mirdid & X & 46 & 3500 & 3500 \\
\hline & İbid & Aramirza & X & 20 & 3000 & 3000 \\
\hline & İbid & Gorshet & X & 11 & 1500 & 1500 \\
\hline & İbid & Villa & X & 26 & 3000 & 3000 \\
\hline & İbid & Belesh & $X$ & 12 & 2000 & 2000 \\
\hline & İbid & Shen Kostandin & $X$ & 11 & 2200 & 2200 \\
\hline $\begin{array}{l}\text { Ymer Iljasi, ushtari i } \\
\text { kalasë së Dukagjinit }\end{array}$ & İbid & Tagmesh & $X$ & 23 & 1400 & 1400 \\
\hline Total & & & 25 & 168 & $199^{\prime} 600$ & $19^{\prime} 400$ \\
\hline
\end{tabular}

\section{Zadrima (166-172/417-428)}

Sipas anëshkrimit në regjistrin e vitit 1571 kazatë e Zadrimës dhe të Rragamit në një regjistër të mëparshëm figuronin me të ardhura 11'766 akçe, ndërsa më pas i qenë caktuar si pronë private (mylk) në muajin shtator të vitit 1524 (Zilkade 930) Mustafa pashës. Akti i dhënies në pronësi (mylkname) të këtyre dy kazave qe depozituar në regjistrin perandorak nga Ibrahim pasha dhe Ajas pasha. ${ }^{17}$

Në një anëshkrim tjetër në regjistrin e vitit 1591 shkruhet se, popullsia e Zadrimës dhe e Rragamit, që nga koha që kalaja e Shkodrës u mor nga sulltan Mehmeti II, qenë përjashtuar nga pagimi i taksave, pasi kryenin shërbime logjistike për kalanë e Shkodrës, më konkretisht ata merreshin me mirëmbajtjen e puseve të kalasë, transportin e drithrave për hambarët e kalasë, mirëmbajtjen e rrugëve dhe urave që shkonin deri në skelën e Lezhës, prerjen e lëndës drusore dhe transportin e saj deri në kalanë e Lezhës, mirëmbajtjen e urës së Gostiqes, punë që kapte vlerën 15’000 akça, kontrollin e dervenit të Skanjës dhe 32 urave në total. Akti i fundit i lëshuar nga financa perandorake që rikonfirmonte përjashtimin e tyre nga taksat kundrejt këtyre shërbimeve mban datën $983 \mathrm{H}^{18}$

17 BOA, TT, D. 499, s. 417; TKGM, D. 62, vr. $113 \mathrm{v}$.

18 TKGM, D. 62, vr. 113r; 


\section{Albanon}

\section{Revistë kulturore}

Zadrima në vitin 1571 kishte nën varësinë e saj 23 fshatra dhe 3 truallishte (mezra): Shelqeti, Midh dhe Baba. ${ }^{19}$

\begin{tabular}{|r|l|c|c|c|c|c|c|c|c|}
\hline & \multicolumn{1}{|c|}{ Fshati } & \multicolumn{2}{|c|}{ Vatra } & \multicolumn{2}{c|}{ Beqar } & \multicolumn{2}{c|}{ Bashtina } & \multicolumn{2}{c|}{ Të ardhura } \\
\hline & & 1571 & 1591 & 1571 & 1591 & 1571 & 1591 & 1571 & 1591 \\
\hline 1. & Ranza & 12 & 24 & 0 & 0 & 1 & 1 & 500 & 770 \\
\hline 2. & Pistull & 9 & 9 & 0 & 0 & 0 & 0 & 350 & 388 \\
\hline 3. & Paçram & 7 & 9 & 0 & 0 & 0 & 0 & 255 & 350 \\
\hline 4. & Çeravina & 24 & 28 & 6 & 4 & 2 & $2+1$ çiftlik & 1030 & 1093 \\
\hline 5. & Shkjeza & 16 & 21 & 2 & 2 & 0 & 0 & 700 & 800 \\
\hline 6. & Dragush & 15 & 18 & 0 & 0 & 2 & 2 & 560 & 630 \\
\hline 7. & Gjadri & 22 & 31 & 3 & 2 & 1 & 1 & 740 & 1000 \\
\hline 8. & Gramshe & 14 & 15 & 3 & 2 & 0 & 0 & 555 & 565 \\
\hline 9. & Qerose & 22 & 31 & 0 & 2 & 0 & 0 & 720 & 1020 \\
\hline 10. & Daj̧ & 15 & 25 & 0 & 0 & 2 & 0 & 625 & 770 \\
\hline 11. & Baba & 21 & 27 & 4 & 2 & 3 & 1 & 850 & 936 \\
\hline 12. & Hajmel & 25 & 35 & 1 & 2 & 4 & 0 & 950 & 1070 \\
\hline 13. & Zojsi & 11 & 14 & 0 & 0 & 0 & 0 & 390 & 473 \\
\hline 14. & Nikli & 13 & 21 & 0 & 0 & 1 & 1 & 435 & 749 \\
\hline 15. & Kashnjeta & 10 & 14 & 0 & 0 & 1 & 0 & 350 & 483 \\
\hline 16. & Nenshat & 33 & 44 & 6 & 5 & 2 & 0 & 1240 & 1433 \\
\hline 17. & Kallmet & 11 & 28 & 5 & 2 & 1 & 0 & 515 & 870 \\
\hline 18. & Troshan & 19 & 24 & 0 & 2 & 1 & 0 & 588 & 793 \\
\hline 19. & Laç & 18 & 24 & 5 & 3 & 0 & 0 & 730 & 858 \\
\hline 20. & Midh & 33 & 40 & 2 & 4 & 0 & 0 & 1062 & 1275 \\
\hline 21. & Blinisht & 38 & 60 & 4 & 4 & 0 & 0 & 1300 & 1263 \\
\hline 22. & Butaç & 14 & 8 & 4 & 1 & 0 & 0 & 611 & 606 \\
\hline 23. & Pema & 12 & 12 & 1 & 3 & 0 & 0 & 325 & 504 \\
\hline Total & & 421 & 562 & 46 & 40 & 20 & $8+1$ çiftlik & $155^{\prime 2} 286$ & $18^{\prime} 699$ \\
\hline
\end{tabular}

\section{Rragami (173-174 / 430-433)}

Kazaja e Rragamit përbëhej nga 10 fshatra në vitin 1571, ndërsa në vitin 1591 janë regjistruar 9 fshatra. Fshati Skanda nuk figuron në vitin 1591, ndërsa në vitin 1571 regjistruesi shkruan se nuk iu gjet nami as nishani gjatë regjistrimit. ${ }^{20}$ Përsa i takon bashtinave ato gjenden në fshatin Kotrr, vetëm 1 në vitin 1571, që nuk figuron më në vitin 1591 dhe në fshatin Radina/ Zadina, 2 bashtina që figurojnë në të dy vitet e regjistrimeve.

19 BOA, TT, D. 499, s. 418-429; TKGM, D. 62, vr. 113r-119r.

20 BOA, TT, D. 499, s. 430-433; TKGM, D. 62, vr. 119r-121r. 


\begin{tabular}{|l|l|c|c|c|c|c|c|}
\hline & \multicolumn{1}{|c|}{ Fshati } & \multicolumn{2}{|c|}{ Vatra } & \multicolumn{2}{c|}{ Beqar } & \multicolumn{2}{c|}{ Të ardhura } \\
\hline & & 1571 & 1591 & 1571 & 1591 & 1571 & 1591 \\
\hline 1. & Vidin & 7 & 5 & 2 & 0 & 690 & 275 \\
\hline 2. & Vjerdha & 11 & 12 & 1 & 2 & 390 & 459 \\
\hline 3. & Busa Shakoll & 7 & 5 & 0 & 0 & 255 & 265 \\
\hline 4. & Lesna & 10 & 9 & 0 & 0 & 320 & 400 \\
\hline 5. & Qyrsak & 3 & 7 & 0 & 0 & 107 & 219 \\
\hline 6. & Mirdija & 8 & 6 & 1 & 1 & 260 & 260 \\
\hline 7. & Mirleshta & 7 & 7 & 0 & 0 & 250 & 250 \\
\hline 8. & Kotrri & 28 & 32 & 3 & 7 & 905 & 1192 \\
\hline 9. & Radina & 7 & 7 & 0 & 0 & 285 & 358 \\
\hline 10. & Skanda & 0 & $X$ & 0 & 0 & 0 & 0 \\
\hline Total & & 91 & 90 & 7 & 10 & 3462 & 3705 \\
\hline
\end{tabular}

